\title{
T.А. Неверова
}

\section{МОДЕЛЬ СОЦИАЛЬНОГО СТАТУСА БИБЛИОТЕКАРЯ ${ }^{1}$}

\begin{abstract}
В статье описана многофакторная модель сочиального статуса библиотекаря, учитывающая множество компонентов: статусную роль, статусные права и обязанности, статусный диапазон, статусные символь, статусный образ, статусную идентификацию, статусное видение мира. Автор считает, что многофакторный подход к формированию сочиального статуса позволит разработать региональные программы повышения сочиального статуса библиотекаря.

Ключевые слова: социиальный статус, модель социального статуса библиотекаря.
\end{abstract}

Социальный статус работника библиотекаря является обобщенным показателем сравнительного положения данной профессии в профессиональноквалификационной структуре регионального сообщества. Исходя из того, что социальный статус профессии характеризует официальное или неофициальное признание ее необходимости и популярности, очевиден дисбаланс данных позиций применительно к сфере культуры.

Следует отметить, что работники культуры представляют собой одну из самых многочисленных социально-профессиональных групп в структуре региональной интеллигенции. В настоящее время в сфере культуры Тамбовской области трудятся около 6000 человек. Это руководители и работники областных и муниципальных библиотек, музеев, театров, концертных учреждений, культурно-досуговых учреждений, парков культуры и отдыха, педагогические работники образовательных учреждений в сфере культуры. Их деятельность связана с удовлетворением культурно-досуговых потребностей населения региона и предоставлением доступа к культурному наследию.

Необходимость изучения социального статуса библиотекаря обусловлена тем, что данная профессиональная группа достаточно многочисленна, а также характеризуется собственным набором ценностей, стереотипами поведения, образом и стилем жизни.

Проблема заключается в противоречии между высоким социальным значением библиотечной деятельности и понижением роли труда, снижением трудовой мотивации, ощущением работниками собственной незначительности в обществе, незакрепляемостью молодых специалистов на рабочем месте.

С одной стороны, наблюдается тенденция повышения экономической составляющей социального статуса библиотекаря в Тамбовской области, а с другой - престижная составляющая социального статуса большинства профессий в сфере культуры остается чрезвычайно низкой.

\footnotetext{
${ }^{1}$ Статья подготовлена при финансовой поддержке РГНФ, проект № 14-13-68004.
} 


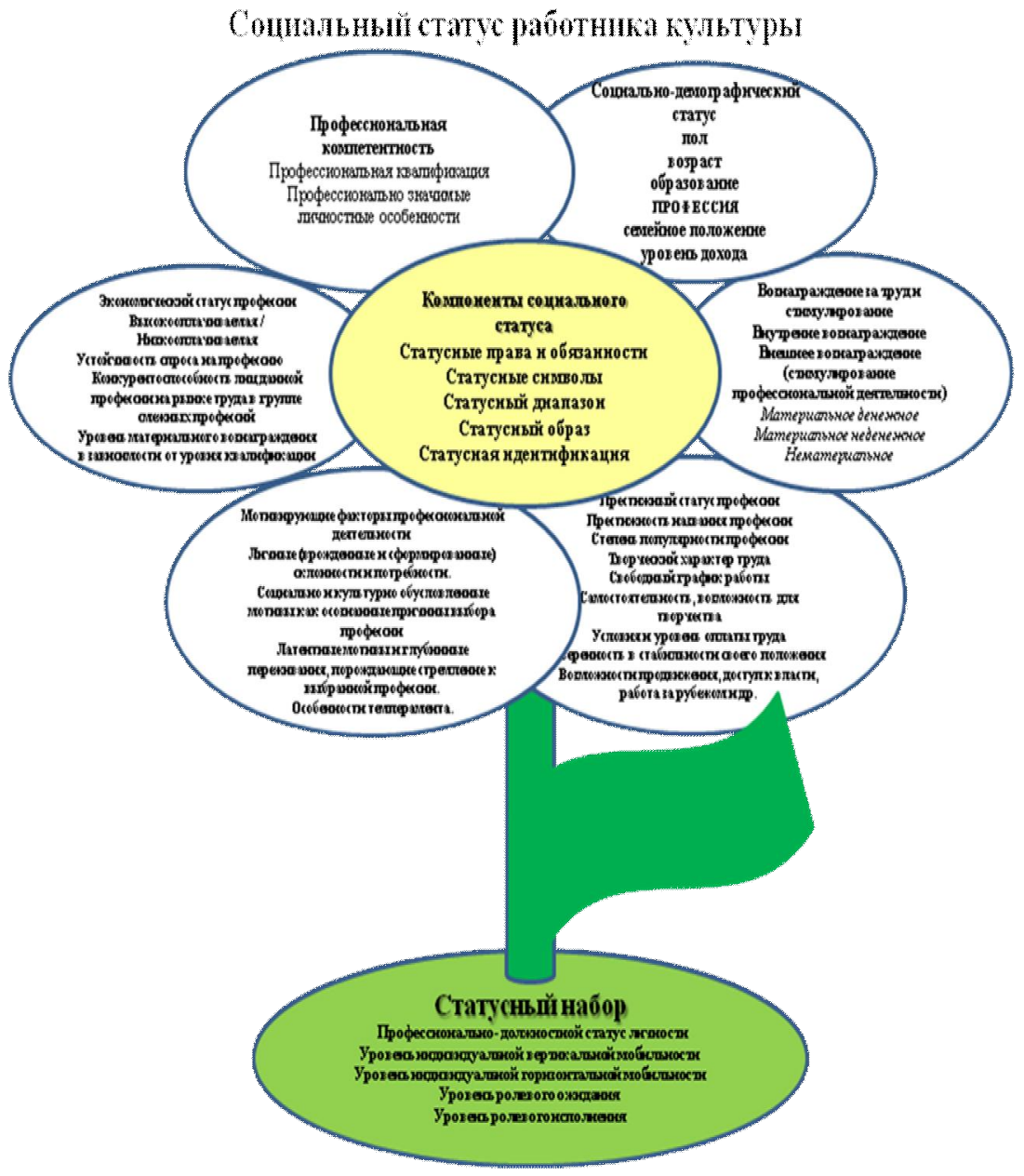

Рис. 1. Модель социального статуса работника культуры

Использование методики социального моделирования позволило разработать модель социального статуса библиотекаря как частный случай модели социального статуса работника культуры с учетом множества факторов, свойств и отношений, оказывающих влияние на социальный статус и социальный престиж работника культуры (рис. 1). Среди основных детерминирующих факторов выделим социально-демографические показатели; социально-профессиональные, экономические, ценностно-мотивационные показатели.

Важным фактором социально-профессионального статуса библиотекаря является его профессиональная компетентность, которая определяется как некое подтвержденное право принадлежности к определенной профессиональной группе работников, признаваемое со стороны социальной системы в целом, представителями данной профессиональной группы, других социальных и профессиональных групп.

Престижный статус профессии обусловлен творческим характером труда, степенью популярности профессии, престижностью названия профессии, ус- 
ловиями и уровнем оплаты труда, самостоятельностью, возможностью для творчества, свободным графиком работы, уверенностью в стабильности своего положения, возможностью продвижения, доступа к власти, работы за рубежом и др. [1. С. 66].

Экономический статус профессии включает такие факторы, как высокооплачиваемая / низкооплачиваемая, устойчивость спроса на профессию, конкурентоспособность лиц данной профессии на рынке труда в группе смежных профессий, уровень материального вознаграждения в зависимости от уровня квалификации.

Следующим важным элементом социального статуса библиотекаря являются мотивирующие факторы профессиональной деятельности, среди которых наиболее важными являются:

1. Личные (врожденные и сформированные) склонности и потребности в определенном виде активности.

2. Социально и культурно обусловленные мотивы как осознанные причины выбора профессии.

3. Латентные мотивы и глубинные переживания, порождающие стремление к выбранной профессии.

4. Особенности темперамента, непосредственно влияющие на то, как именно личность реализует себя в профессиональной деятельности.

Совокупность этих факторов образует мотивационный контур, который приводит личность в профессию.

Конкретный набор трудовых мотивов зависит от трудовой ситуации и жизненных обстоятельств, в совокупности образуя мотивационное ядро профессиональной деятельности.

Существенным фактором, оказывающим влияние на социальный статус библиотекаря, является вознаграждение за труд и стимулирование. В модели социального статуса важно учитывать как внутренние (чувство достижения результата, чувство содержательности и значимость работы, самоуважение, общение с коллегами), так и внешние формы вознаграждения, которые стимулируют профессиональную деятельность работника культуры. Здесь важно различать материальное денежное вознаграждение (заработная плата, премии, надбавки, бонусы), материальное неденежное вознаграждение и нематериальное вознаграждение. Например, материальное неденежное вознаграждение включает стимулирование рабочим временем (укороченный пятый день, четырехдневная неделя по 8 часов, удлиненный отпуск, гибкий график работы, получение дополнительных отгулов, возможность раньше уходить домой), стимулирование рабочим местом и условиями труда (предоставление средств связи, кондиционера, отдельного кабинета и т. д.; оплата услуг связи, представительские расходы; обеспечение спецодеждой и создание благоприятных условий работы), стимулирование льготными программами (наличие программ отдыха (путевки, экскурсии), обеспечение профессионального развития (стажировки, тренинги), обеспечение литературой, пенсионные и налоговые программы, наличие клубных программ) [2. С. 23].

В стимулировании работников культуры и библиотечных работников, в частности, традиционно важную роль играет нематериальное вознаграждение. Однако не все группы стимулов задействованы эффективно, поэтому 
при построении модели социального статуса работника культуры важно учитывать весь спектр стимулов:

- социальные стимулы (повышение престижности труда, возможность профессионального роста, возможность самоутверждения);

- моральные стимулы (устная похвала, вынесение благодарности, различные награждения);

- творческие стимулы (самореализация, самосовершенствование, самовыражение);

- социально-психологические стимулы (возможность общения, причастность к делам группы).

Таким образом, социальный статус и престиж библиотекаря необходимо формировать в региональной среде. Разработанная модель позволяет учесть множество свойств и отношений, оказывающих влияние на социальный статус и социальный престиж библиотекаря.

\section{Литература}

1. Неверова T.A. Тренинговые формы обучения в повышении социального статуса библиотекарей региона // Вестн. Тамбов. гос. ун-та. Сер. Гуманит. науки. 2014. № 4. С. 64-69.

2. Давыдова С.Б. Мотивация профессиональной деятельности: учеб. пособие. М.: МГУКИ, $2014.96 \mathrm{c}$.

Neverova Tatyana A. Tambov State University (Tambov, Russian Federation). E-mail: nev_tat@mail.ru. DOI 10.17223/22220836/17/21

\section{MODEL OF SOCIAL STATUS LIBRARIAN}

Key words: social status, model of the social status of the librarian.

Article describes a multifactor model of the social status of the librarian, that takes into account a number of components: the role of the status, rights and duties of the status, the status range, status symbols, the status image, status identification, status view of the world. The author believes that a multifactorial approach to the formation of social status will develop regional programs to improve the social status of the librarian and involvement of young people in the librarian sphere.

Specific set of labor depends on the motives of the labor situation and the circumstances of life, together forming the core motivation of professional activity. In the promotion of cultural workers and library workers, in particular, traditionally plays an important role intangible rewards. However, not all groups involved incentives effectively, so the construction of model the social status of culture, it is important to take into account the whole range of incentives. Thus, the social status and prestige of the librarian should be formed in the regional environment. The developed model allows to take into account a number of properties and relationships that affect the social status and social prestige of the librarian.

\section{Refereces}

1. Neverova T.A. Treningovyye formy obucheniya v povyshenii sotsial'nogo statusa bibliotekarey regiona // Vestn. Tamb. gos. un-ta. Ser. Gumanit. nauki. 2014. № 4. P. 64-69.

2. Davydova S.B. Motivatsiya professional'noy deyatel'nosti: ucheb. posobiye. M.: MGUKI, 2014.96 p. 